\title{
Bus Rapid Transit: An Overview
}

\author{
Herbert S. Levinson, Transportation Consultant \\ Samuel Zimmerman and Jennifer Clinger, DMJM+Harris \\ C. Scott Rutherford, University of Washington
}

\begin{abstract}
Bus Rapid Transit (BRT) is growing in popularity throughout the world. The reasons for this phenomenon include its passenger and developer attractiveness, its high performance and quality, and its ability to be built quickly, incrementally, and economically. BRT also provides sufficient transport capacity to meet demands in many corridors, even in the largest metropolitan regions. In the United States, the development of BRT projects has been spurred by the Federal Transit Administration's (FTA) BRT initiative. These projects have been undertaken, in part, because of the imbalance between the demand for "New Starts" funds and available resources.

Decisions to make BRT investments should be the result of a planning process that stresses problem solving, addressing needs, and the objective examination of a full range of potential solutions, of which BRT is only one. Good planning practice means matching potential market characteristics with available rights-of-way. BRT involves an integrated system of facilities, services, amenities, operations, and Intelligent Transportation Systems (ITS) improvements that are designed to improve performance, attractiveness to passengers, image, and identity. Because they can be steered as well as guided, BRT vehicles can operate in a wide range of environments without forcing transfers or requiring expensive running way construction over the entire range of their operation. Through this flexibility, BRT can provide one-seat, high-quality transit performance over a geographic range beyond that of dedicated guideways. To the
\end{abstract}


maximum extent practical, the system should transfer the service attributes of rail transit to BRT.

Even where implementation of a comprehensive, integrated BRT system is not possible, many of its components can be adapted for use in conventional bus systems with attendant benefits in speed, reliability, and transit image/attractiveness.

In summary, BRT is growing in popularity because it can be cost-effective and it works. This article describes BRT concepts and components, traces BRT's evolution, gives its current status, and outlines some of the findings to date of the Transportation Research Board's (TRB) Transit Cooperative Research Program (TCRP) A-23 project, "Implementation Guidelines for Bus Rapid Transit."

\section{Introduction: What Is BRT?}

The FTA defines BRT as a "rapid mode of transportation that can combine the quality of rail transit and the flexibility of buses" (Thomas 2001).

A more detailed definition, which was developed as part of the TCRP A-23 project, is:

BRT is a flexible, rubber-tired rapid transit mode that combines stations, vehicles, services, running way, and ITS elements into an integrated system with a strong positive image and identity. BRT applications are designed to be appropriate to the market they serve and their physical surroundings and can be incrementally implemented in a variety of environments.

In brief, BRT is a permanently integrated system of facilities, services, and amenities that collectively improve the speed, reliability, and identity of bus transit. In many respects, BRT is rubber-tired light rail transit (LRT), but with greater operating flexibility and potentially lower capital and operating costs.

While BRT is often compared to LRT, other comparisons with rail modes may be more appropriate:

- Where BRT vehicles (buses) operate totally on exclusive or protected rights-of-way, the level of service provided can be similar to that of full Metrorail rapid transit. 


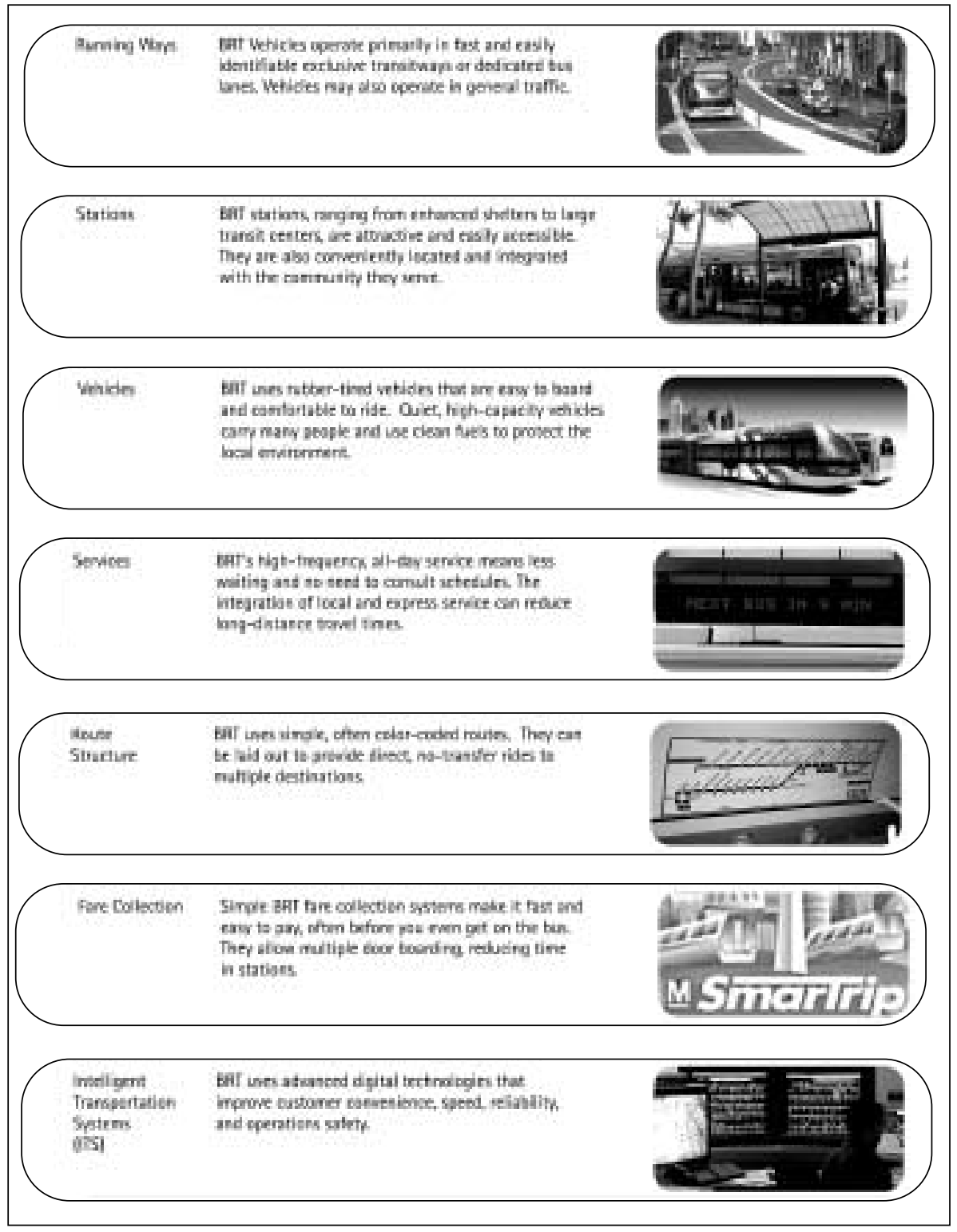

Figure 1. Components of Bus Rapid Transit 
- Where buses operate in combinations of exclusive rights-of-way, median reservations, bus lanes, and street running, the level of service provided is very similar to LRT.

- Where buses operate mainly on city streets in mixed traffic, the level of service provided is similar to a limited-stop tram/streetcar system.

There are seven major components of BRT which relate to the key quality transit attributes of speed, reliability, and identity. Figure 1 describes these components in detail. Collectively, they form a complete rapid transit system that can improve customer convenience and reduce delays compared to local bus and street/trolley car systems (BRT Bus Rapid Transit 2001).

\section{Why BRT?}

There are many reasons for developing BRT systems, especially in a U.S. context.

1. Central business districts (CBDs) have continued to prosper and grow in ways that require more transport capacity and improved access, even though employment in U.S. CBDs is declining as a percentage of overall regional activity. Given the cost and environmental impacts associated with parking and road construction and the traditional urban form of most CBDs, improved and expanded public transport emerges as an important alternative for providing that capacity. In addition, many suburban-edge cities exceed the aggregate employment base of many bigcity CBDs but do not currently have the focus and density to make railbased rapid transit a cost-effective investment.

2. BRT systems can often be implemented quickly and incrementally.

3. For a given distance of dedicated running way, BRT is generally less costly to build than rail transit. Moreover, where BRT vehicles can reliably operate at high speeds on high-occupancy vehicle (HOV) lanes or general-purpose highways and streets over significant proportions of a given route, running way capital costs will be even lower compared to those for rail modes, which must be purpose-built over the entire distance covered. 
4. BRT can be the most cost-effective means of serving a broad variety of urban and suburban environments. BRT vehicles-whether they are driver-steered or electronically guided-can operate on streets, in freeway medians, on railroad rights-of-way, on aerial structures, and underground. BRT systems can also provide a broad array of express, limited-stop, and local all-stop services on a single facility without complex signal and guideway switching systems.

5. BRT can provide quality performance with sufficient transport capacity for most corridors in U.S. and Canadian cities. For example, the Ottawa transitway system's link to the CBD carries more people in the peak hour than most LRT segments in North America. The Brisbane South East Busway carries approximately the same number of maximum load point, peak-hour, peak-direction passengers-about 10,000 per hour. Many BRT lines in South American cities carry peak-hour passenger flows that equal or exceed those on many U.S. and Canadian fully grade-separated rail rapid transit lines. For example, Bogota's TransMillenio system serves more than 25,000 peak-hour, peak-direction maximum load point riders.

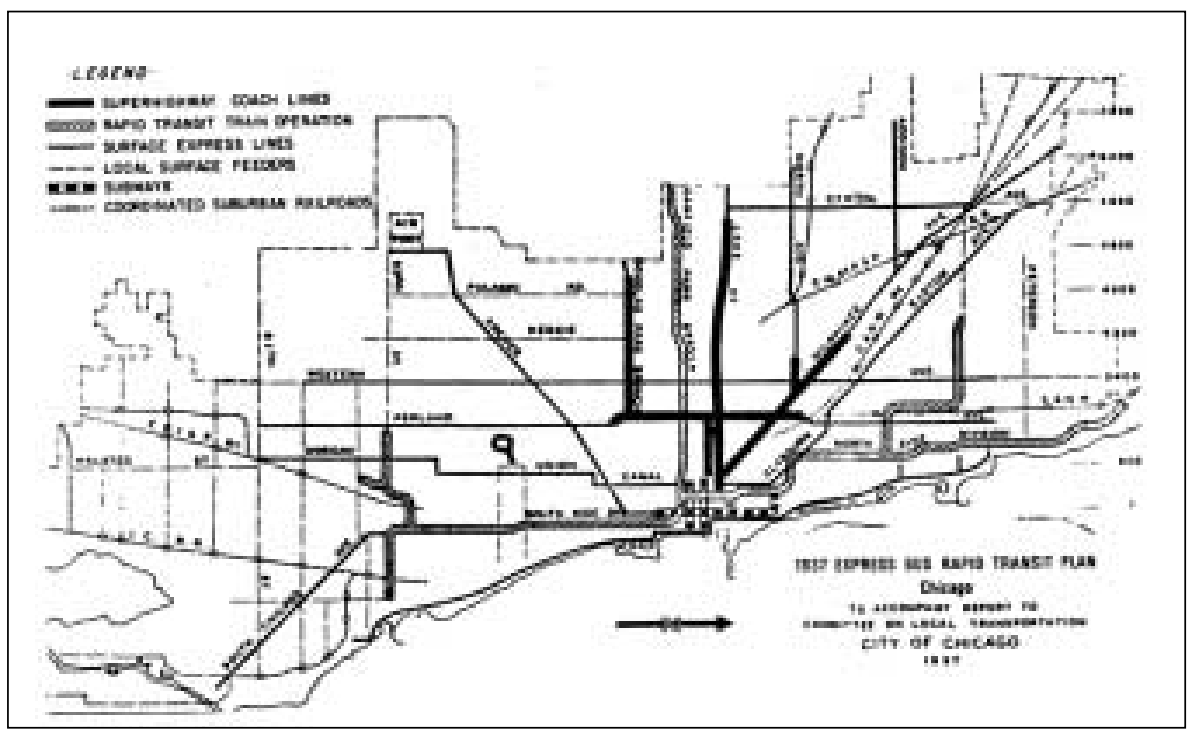

Figure 2. 1937 Express Bus Rapid Transit Plan-Chicago 
6. BRT is well suited to extend the reach of rail transit lines providing feeder services to/from areas where densities are too low to cost effectively extend the rail corridor. Examples of this application are the South Dade Busway in South Miami-Dade County and the Pie IX Busway in Montreal.

7. BRT can be integrated into urban environments in ways that foster economic development and transit- and pedestrian-friendly design. For example, in Boston, Ottawa, and Brisbane, BRT has been part of integrated transit and land-use strategies.

\section{Evolution of BRT}

The concept of bus rapid transit is not new. Plans and studies for various BRTtype alternatives have been prepared since the 1930s, although there has been a greater emphasis on BRT in recent years than ever before.

\section{Major Proposals}

BRT proposals were developed for Chicago in 1937, Washington D.C. in 1956-1959, St. Louis in 1959, and Milwaukee in 1971. A brief discussion of these plans follows.

1937 Chicago Plan. The concept of bus rapid transit was first suggested in Chicago (Harrington, Kelker, and DeLeuw 1937). A 1937 plan (Figure 2) called for converting three west-side rail rapid transit lines to express bus operation on superhighways with on-street distribution in central areas and downtown.

1955-1959 Washington D.C. Plan. Design studies for BRT within freeway medians were developed as part of the 1956-1959 Transportation Survey for the National Capital Region (Mass Transportation Survey 1959). It was recommended that

in planning of future radial freeways a cross section ... be provided to afford maximum flexibility and reserve capacity for vehicles as well as for the mass movement of people. Under this plan there would be a three- or four-lane roadway for traffic in each direction. These roadways would be separated by a 64-foot mall with 51 feet from center-to-center of the columns supporting cross-street bridges. In the first stage, this wide mall would be landscaped and held available for 


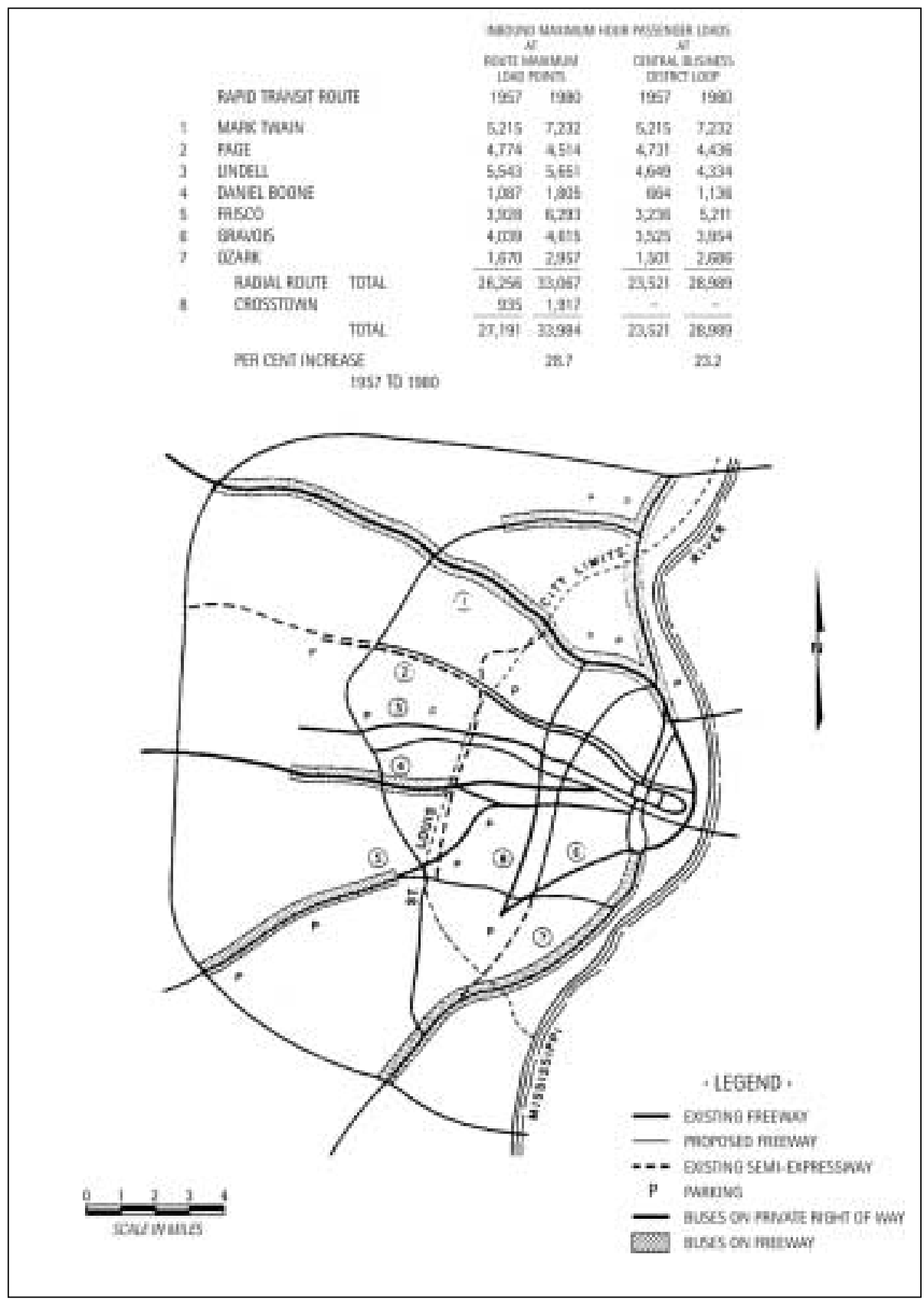

Figure 3. Proposed Regional Bus Rapid Transit Plan-St. Louis, 1959 
future developments; public transportation would consist of express buses operating in the general traffic lanes. They would make stops at appropriate intervals on the parallel service roads without special station facilities or at simple stations within the end span of the crossstreet bridges.

Express bus service eventually would be converted to BRT and rail within the median.

1959 St. Louis Plan. The 1959 Transportation Plan included an 86-mile BRT system, of which 42 miles were to be on special grade-separated bus roadways (W. C. Gilman and Co. 1959). Figure 3 shows the arrangement of the proposed busways and BRT lines. The focus of this proposal was an elevated loop road encircling part of downtown St. Louis, measuring six blocks north and south and five blocks east and west. The loop contained a 60-foot-wide operating deck that included a sidewalk, or passenger-loading platform, located on the inner side of the deck to mesh with one-way clockwise operation of buses. It provided a three-lane bus roadway approximately 37 feet wide. The BRT system cost totaled $\$ 175$ million (exclusive of freeways).

1970 Milwaukee Transitway Plan. Milwaukee's proposed 1990 Transitway Plan included 107 miles of express bus routes over the freeway system plus an 8-mile east-west transitway (Barton-Aschman Associates 1971). The plan, shown in Figure 4, called for 39 stations (excluding downtown) and 33,000 parking spaces. During the 1990 design-hour, 600 buses would enter the Milwaukee CBD as compared with 135 in 1973. Costs for the BRT transit system were estimated at $\$ 151$ million (1970) of which $\$ 40$ million were for the transitway. The plan was integrated with existing and proposed freeways.

\section{Concept Studies}

Several planning research studies have described the parameters where BRT would work and how it might be configured.

Transportation and Parking for Tomorrow's Cities. This 1966 study set forth broad planning guidelines (Wilbur Smith and Associates 1966). It indicated that bus rapid transit is especially suitable in cities where downtown most attracts its visitors from a wide, diffused area. It stated:

$B R T$ could involve lower capital costs, provide greater coverage, better serve low- and medium-density areas, and more readily adapt to 
changing land-use and population patterns than rail systems. BRT also has applicability in larger cities of much higher density because of its operational flexibility, and that with proper downtown terminal design, bus rapid transit systems could provide adequate capacities to meet corridor demands in nearly all of the Nation's cities which did not have rail systems.

To achieve high average speeds on downtown approaches, buses could operate within reserved lanes or exclusive freeway rights-of-way on key radial routes and travel outward to the intermediate freeway loop, with provision for subsequent expansion (Figure 5). Downtown, buses would operate preferably on private rights-of-way and penetrate the heart of the core area (either above or below ground) or, alternatively, they could enter terminals.

Successful BRT, however, would require .. careful coordination between highway and transit officials in all stages of major facility planning. In this regard, resolution of several major policy questions will go far toward early implementation of BRT systems. These questions include:

1. extent to which exclusive bus facilities will quality for federal aid under existing programs,

2. need for separate designs on approaches to the inner freeway loops and downtown,

3. minimization or elimination of costly ventilation systems to facilitate underground operation,

4. development of financing policies for downtown bus tunnels, and

5. development of bus trains or special bus designs to minimize downtown station requirements and expedite downtown loading.

The report indicated that a small amount of special right-of-way in conjunction with the urban freeway system (where necessary to assure good peakhour speeds) could generally provide effective regional rapid transit.

It was conservatively estimated that freeways, BRT, local transit, and arterials under existing capabilities of cars and buses could accommodate peak-hour 


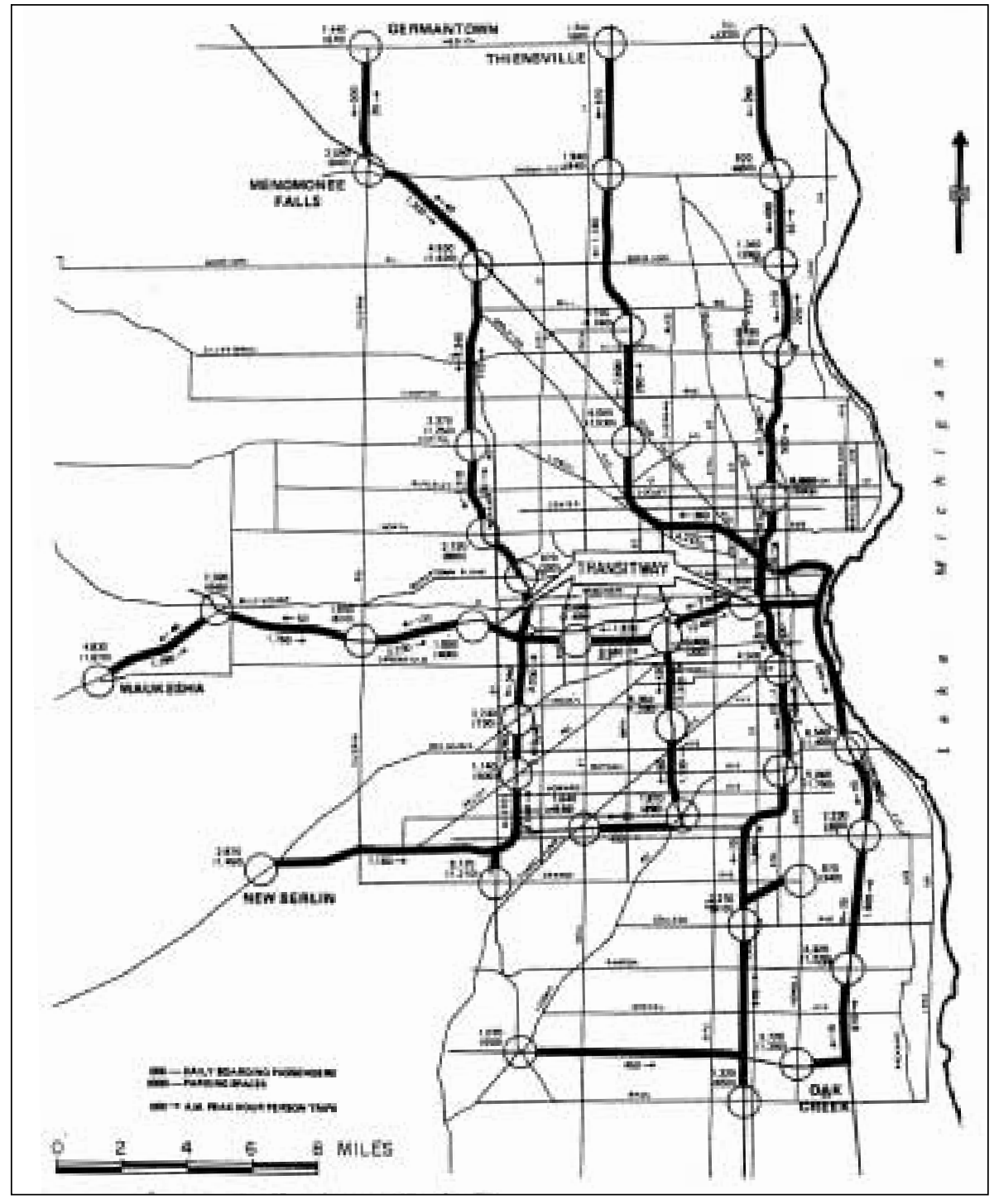

Figure 4. Proposed 1990 Milwaukee Transitway Plan 
downtown cordon volumes of up to 125,000 persons - ample capacity for the vast majority of the nation's cores. Moreover, as bus technology improves and electronic bus train operation becomes a reality, substantially greater capacities would be achieved. "Thus, ultimately, differences between rail and bus transit could become minimal."

The Potential for Bus Rapid Transit. This 1970 study indicated that freeway systems are potentially usable by express buses and, with modification, for exclusive bus lanes or busways (Wilbur Smith and Associates 1970). Key factors in evaluating the potential benefits of BRT include: (1) capital costs, (2) operating costs, (3) route configuration, and (4) distribution in the city center and other major activity centers.

NCHRP Reports 143 and 155 (1973, 1975) on Bus Use of Highways. These reports provided a comprehensive review of the state of the art and set forth planning and design guidelines (Levinson et al. 1973, 1975). Using the goal of minimizing total-person delay as a guide, these reports suggested ranges in peakhour bus volumes for bus priority facilities. The guidelines, shown in Table 1, were based on "design year" peak-hour bus volumes.

Figure 6 shows the range in BRT service concepts set forth in Report 155 that are still relevant today.

Bus Rapid Transit Options for Densely Developed Areas. This 1975 study (Wilbur Smith and Associates 1975) described and evaluated the cost, service, and environmental implications of bus lanes, bus streets, and busways. The report showed how various bus priority facilities would be coordinated in the central area (Figure 7) and suggested a multidoor articulated bus for BRT operations.

Most of these concept studies focused on the facility aspects of BRT, often as an adjacent to urban freeways. Little attention was given to the service and amenity/identify aspects of BRT.

\section{Countervailing Trends}

In the late 1970s, the emphasis in transit planning shifted from bus use of highways and BRT to HOV lanes and LRT. HOV lanes were perceived as having widespread application as an environmentally positive way of expanding 


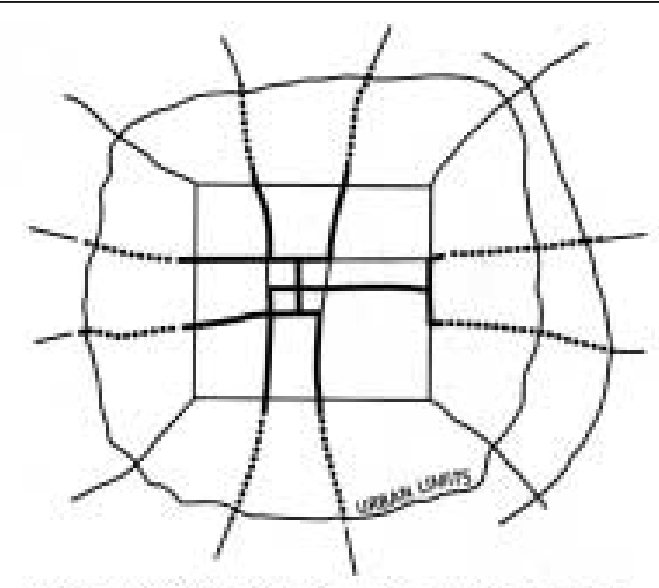

BUS-WAYS THROUGH HIGH DENSITY AREA

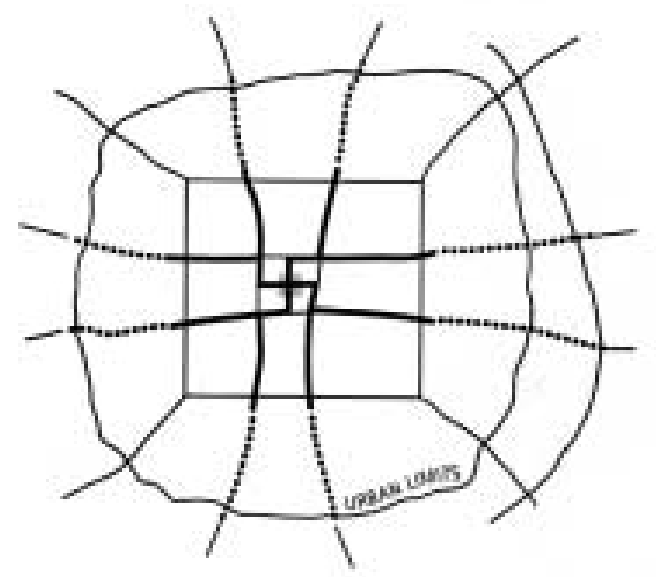

LEGEND

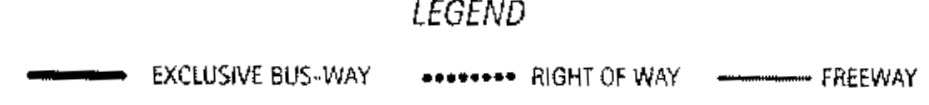

Figure 5. Configuration of hypothetical BRT systems

These schematic systems show how a relatively small mileage of special bus rights-of way can provide areawide rapid transit by utilizing freeway systems as an integral part of their operation. Radial freeways could provide amply wide medians to permit extension of buslanes (or rights-of-way) as required by future growth. Off-street bus-ways penetrate the heart of downtown and (where feasible) high-density areas. In some cases, metering of freeway traffic might serve as an alternative to exclusive lanes. 


\begin{tabular}{|c|c|}
\hline \multicolumn{2}{|c|}{$\begin{array}{c}\text { Table } 1 \\
\text { Suggested Ranges in Peak-Hour (One-Way) Bus Volumes for Bus } \\
\text { Prionity Facilities }\end{array}$} \\
\hline Type of Treatment & $\begin{array}{c}\text { No. of Design-Year } \\
\text { Buses }^{a}\end{array}$ \\
\hline $\begin{array}{l}\text { Freeway-related: } \\
\text { Busway } \\
\text { Contra-flow bus lane } \\
\text { Bus bypass lane at metered ramp } \\
\text { Arterial-related: }^{d} \\
\text { Bus streets }^{\mathrm{e}} \\
\text { CBD curb lanes, main street } \\
\text { Curb lanes } \\
\text { Median bus lanes } \\
\text { Contra-flow bus lanes, extended } \\
\text { Contra-flow bus lanes, short segments }\end{array}$ & $\begin{array}{l}20-30 \\
20-30 \\
30-40 \\
60-90 \\
40-60 \\
20-30\end{array}$ \\
\hline $\begin{array}{l}\text { a. Existing conditions should meet } 75 \text { pe } \\
\text { b. Busway installation should generally } \\
\text { employment of at least } 50,000,20 \text { mil } \\
\text { space downtown, and a metropolitan p } \\
750,000 \text {. } \\
\text { c. Contra-flow bus lanes are contingent } \\
\text { traffic volumes. } \\
\text { d. Where arterial bus volumes are less th } \\
\text { use bus lanes. } \\
\text { e. Environmental considerations may inf } \\
\text { street installation. }\end{array}$ & $\begin{array}{l}\text { ent of these volumes. } \\
\text { contingent on a CBD } \\
\mathrm{n} \text { square feet of floor } \\
\text { ulation of at least } \\
\text { directional imbalances in } \\
60 \text { per hour, taxis may } \\
\text { ence bus lane and bus }\end{array}$ \\
\hline
\end{tabular}

road capacity while reducing single-occupant vehicle (SOV) use. LRT lines were increasingly popular, in part, because they were perceived to have performance, quality, image, and service attractiveness that were unattainable by bus transit. While a few communities built busways and operated successful BRT lines over them (e.g., Ottawa and Pittsburgh), LRT was the favored mode, often to the exclusion of serious, objective consideration of BRT or other types of significant bus improvements in federally required planning processes. 
(1) IDEALIED TURNBACK (EQUAL CUTBACK AT EACH POINT) Center City

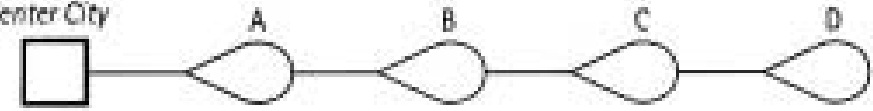

(2) IDEALIZED TURNBACK WITH FREEWAY OR ARTERIAL EXTENSIONS

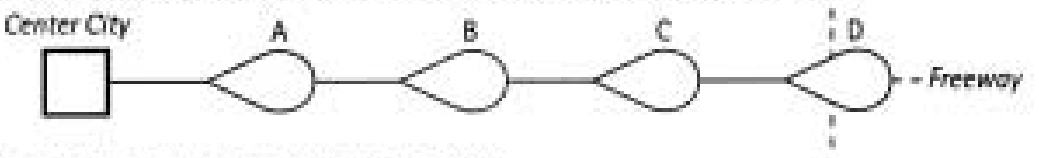

(3) LIMITED SERMCE - TRUNK LINE ONLY Center City

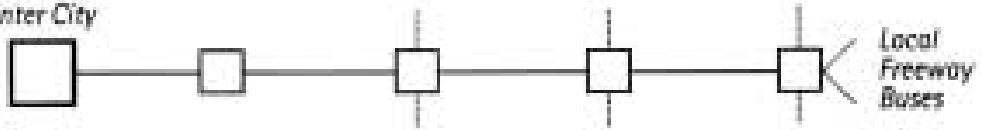

(4) UMITED SERMICE - TRUNK LINE WITH FAEEWAY OR ARTERIAL EXTENSION Center City

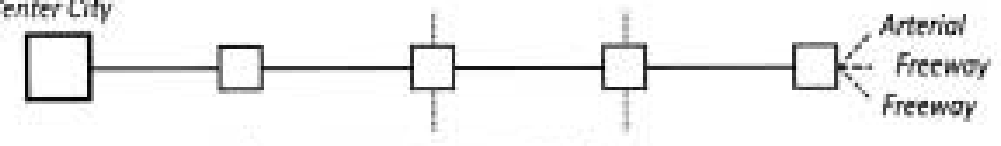

(5) EXPRESS SERVICE (WITH SURFACE EXTENSION)

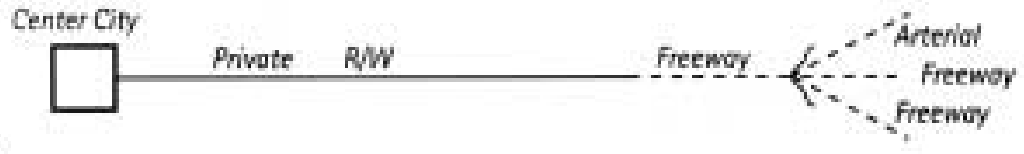

(6) COMBINATION OF EXPAESS AND LOCAL SERVICE EXTENSION Center Cry

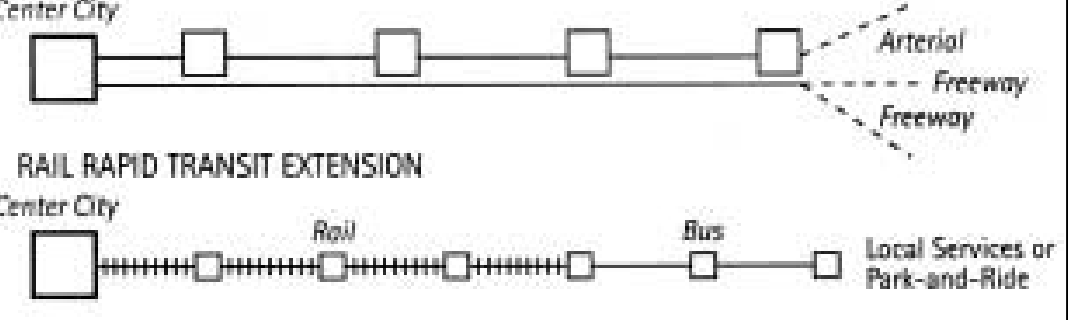

(7) RAIL RAPID TRANSIT EXTENSION Center Oty

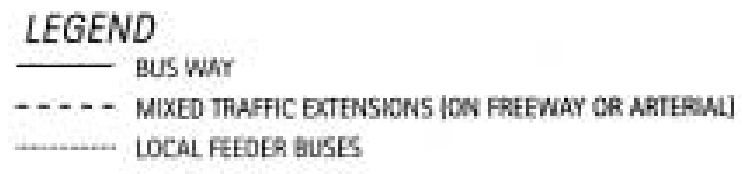

Source: NCHRP 155.

Figure 6. BRT operating concepts 


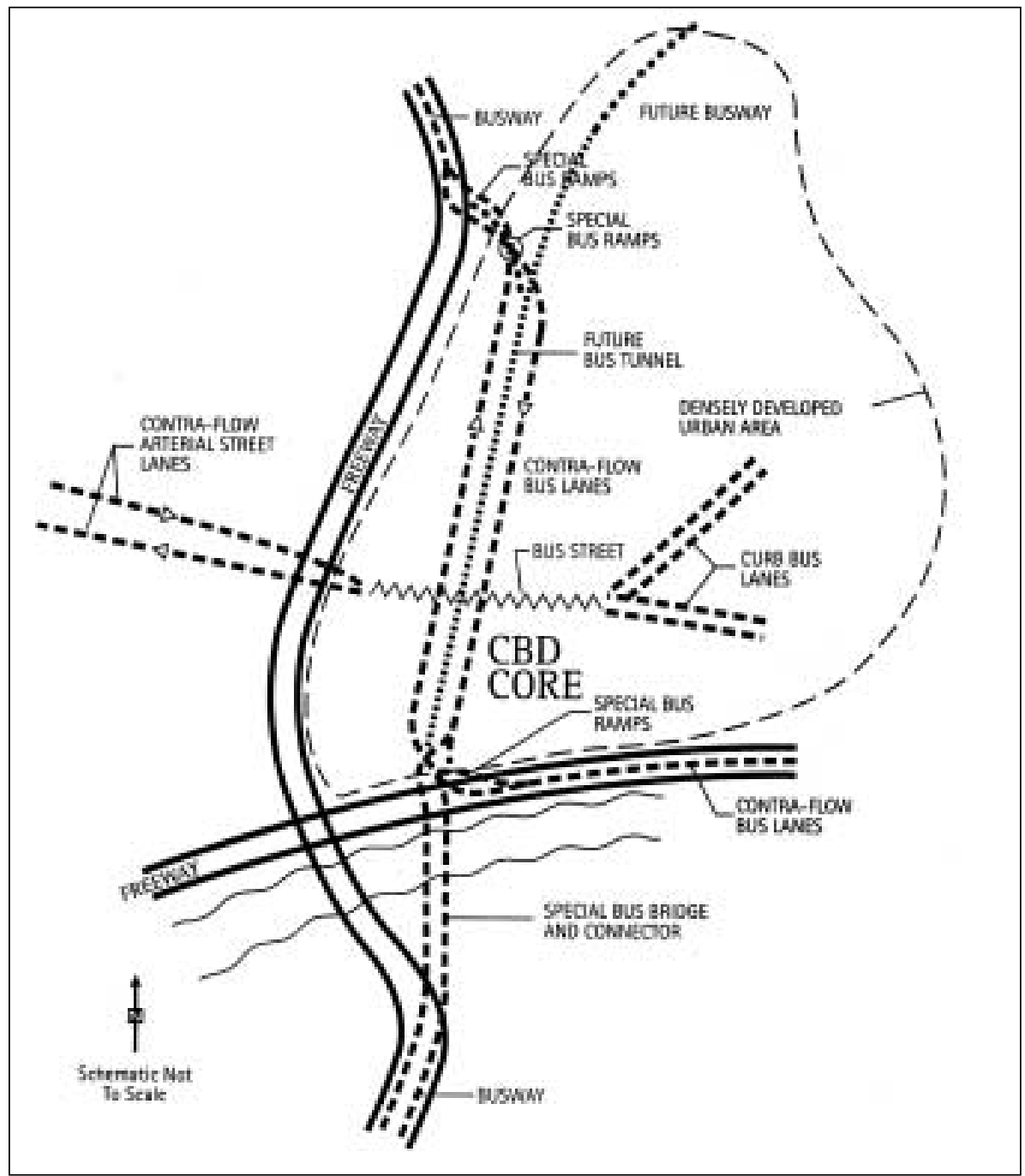

Figure 7. Illustrative coordination of bus prionity facilities

\section{Recent Initiatives}

The federal BRT initiative is a major attempt to redress this balance. Initially using Curitiba's successful BRT system as a "model," the FTA sponsored a BRT conference in 1998, published major documents highlighting BRT (Federal Transit Administration 1987, 1990), established a BRT Consortium (1999) with 17 supporting cities, and launched a BRT demonstration program. 
Concurrently, TCRP A-23 project "Implementation Guidelines for Bus Rapid Transit" was launched by the TCRP.

\section{Current Status of BRT Implementation}

BRT systems now operate in major cities throughout North America, Europe, Latin America, Australia, and New Zealand.

\section{United States and Canada}

About 20 BRT systems are in service, under construction, or in planning in the United States and Canada (Figure 8). These systems vary widely in extent, components, design and operating features, usage, costs, and benefits. Ottawa and Pittsburgh have the most extensive and heavily utilized busway systems that provide service through the city center. Both operate express and all-stop services, and both have experienced development along the busways. The following sections provide a summary of the most advanced BRT projects in the United States and Canada.

Ottawa. The Ottawa transitway system was implemented in phases since 1982. It includes 15.5 miles of exclusive busway, 7.5 miles of lanes on roadway, and 2 miles of downtown bus-only lanes. Twenty-two stations are located along the transitway; and park-and-ride lots at the ends of the facility contain approximately 2,200 spaces.

A variety of transit services are operated on the Ottawa transitway. An allstops, local bus route operates exclusively on the transitway, much like a rail system. Other routes start in neighborhood areas and then access the facility for an express run for a major portion of their trip. Approximately 50 routes provide residents with peak-period, transfer-free express service; off-peak many of these routes operate as feeders to all-stop local routes.

The transitway carries approximately 200,000 riders daily, about 10,000 one-way in the A.M. peak hour at the maximum load point.

Pittsburgh. This City has three busways in operation. The South Busway, opened in 1977, is approximately 4 miles in length and includes nine stations. Buses share a right-of-way through the Mount Washington Tunnel in the Palm Garden Station area with light-rail vehicles. The 6.8-mile Martin Luther King East Busway, opened in 1983, is located on an existing right-of-way and 


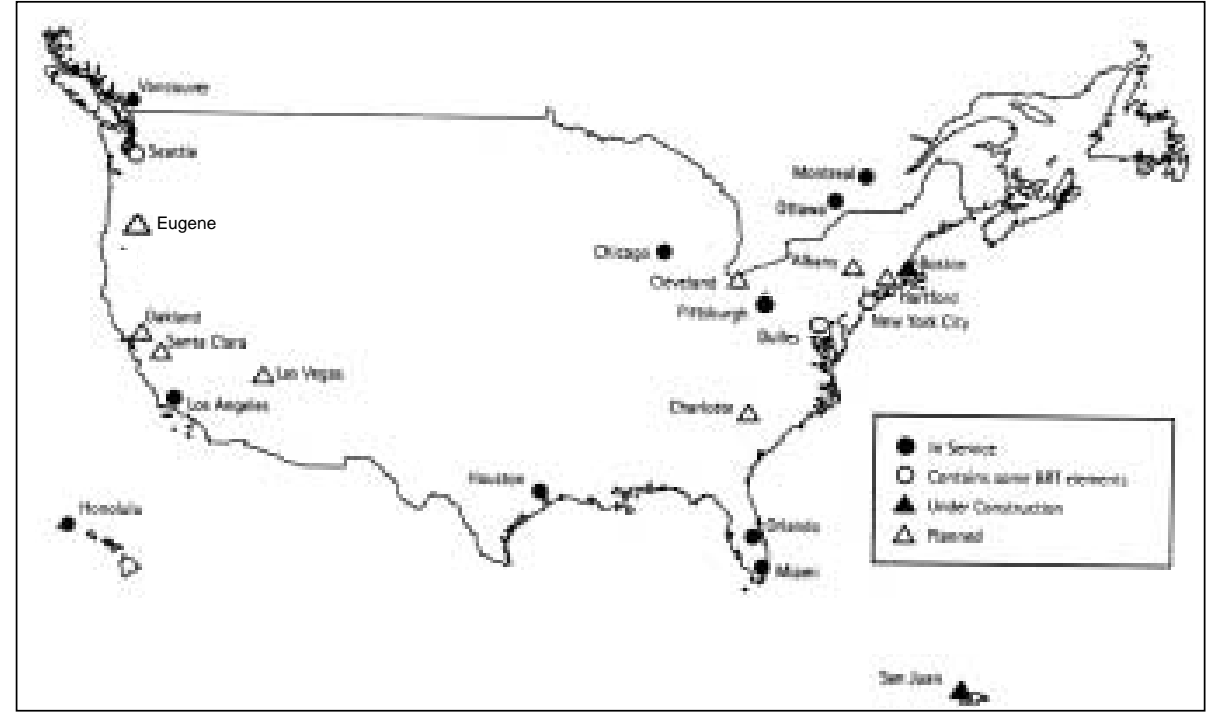

Figure 8. U.S. and Canadian BRT systems

includes six stations. The 5-mile West Busway, opened in September 2000, is also located on a former railroad right-of-way and has six stations. Approximately 2,800 additional parking spaces are provided in park-and-ride lots, including four near the busway. The East and West Busways operate both express and all-stop local services. Weekday ridership averages 28,600 on the East Busway, about 15,000 on the South Busway, and 8,000 trips on the West Busway (expected to rise substantially when 2,000 parking spaces, currently under construction, open).

Miami. Miami has a busway (South Dade) along an abandoned rail line that connects with the Metro rail line and carries about 14,000 weekday riders. Both express and local services are provided along the busway.

Montreal. This City has a feeder BRT line (via a reversible arterial bus lane) that connects to the Pie IX Metro rapid transit station.

Houston. An extensive system of commuter express service operates via bus/HOV lanes with special dedicated "T" access ramps connecting to park-andride lots. Downtown distribution is via curb-bus lanes.

Los Angeles. This City operates the MetroRapid Bus service on Wilshire-Whittier and Ventura Boulevards. Both routes are easily identifiable 
with red-colored low-flow, low-pollution buses running limited-stop service from farside stations (local route use nearside stops) (Figure 9).

MetroRapid buses serve as extensions of the Red Line subway both to the San Fernando Valley (via Ventura Boulevard from the Universal City Metrorail Station) and west on Wilshire Boulevard from the Vermont station. Buses can extend or advance the green time at selected traffic signals. Operating speeds have increased about 29 percent in the Wilshire-Whittier corridor and ridership has increased by 33 percent. In the Ventura Boulevard corridor, operating speeds increased by 23 percent and ridership grew by roughly 26 percent. One-third to one-half of the increased ridership comes from riders new to transit (Metropolitan Transportation Authority 2000). Two-thirds of the travel time savings result from the wider stop spacing.

Vancouver. The 98-B Line BRT between downtown Vancouver and Richmond uses multidoor, low-floor articulated buses. The BRT lines operate with limited stops, feature attractively designed stations, and use a bus-only street in Richmond (Figure 10). Vancouver's 99-B line provides a similar crosstown service from east to west.

Seattle. A bus-only subway runs through Seattle's CBD. Dual-mode articulated buses provide local and express service in outlying areas via freeways and HOV lanes. Some buses run on express service via I-5 to the north and then connect to a short busway running south.

Boston. Boston's Silver Line South Piers Transitway, which is currently under construction, will include both curb bus lanes and a bus subway. Viewed as a fifth rapid transit line using special dual-mode (electric trolley and fullpower diesel) articulated multidoor vehicle, it will link the South Station (Red Line Subway, commuter rail, Amtrak, and intercity bus) and Financial District with the South Piers and Dudley Square on the MBTA's Orange Subway Line. BRT express service will also extend over the existing Ted Williams Tunnel to Logan International Airport (Figure 11).

\section{Overseas Experience}

A broad range of BRT systems and features are found in South America, Europe, and Australia. 


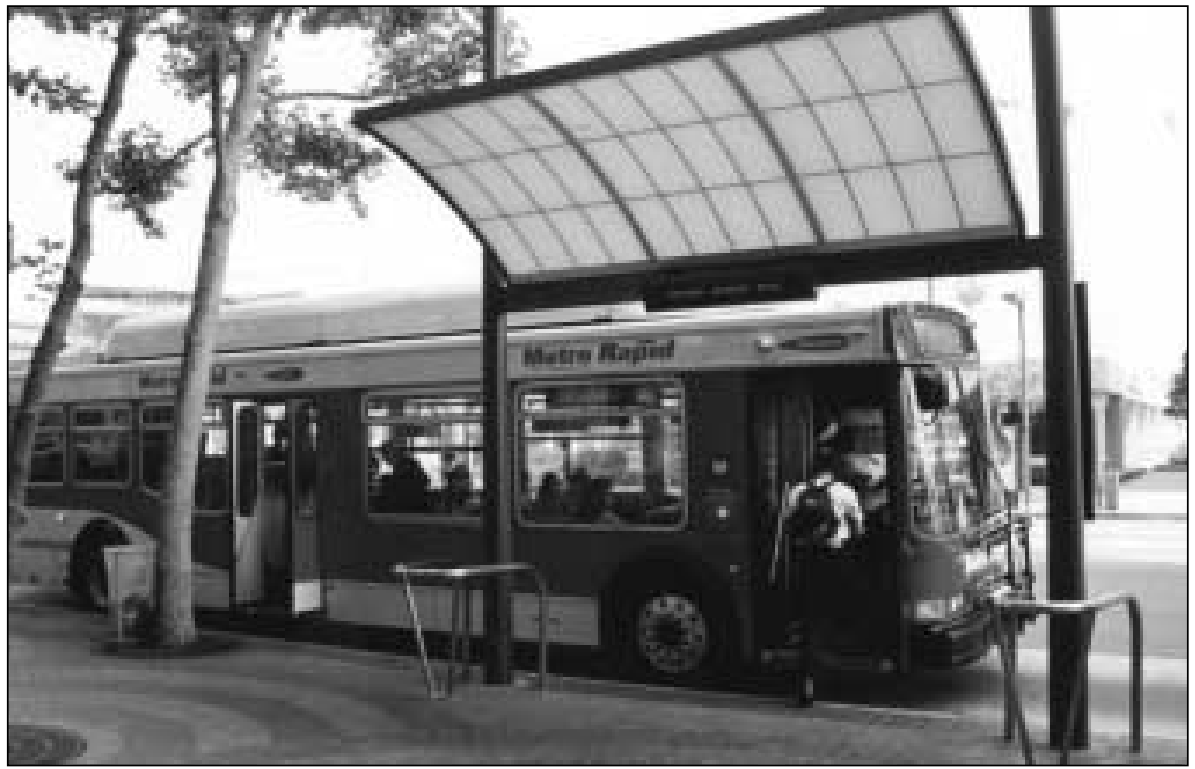

Figure 9. Bus stop, MetroRapid, Los Angeles

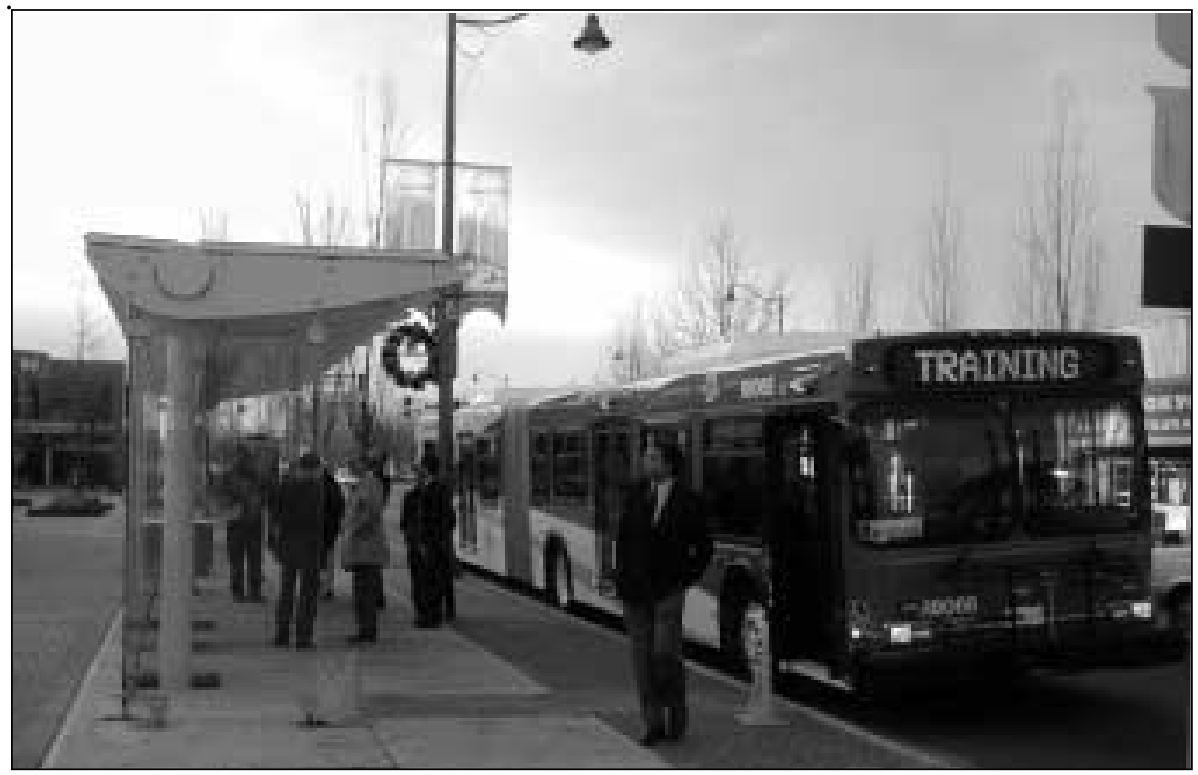

Figure 10. Vancouver's BRT lines operate with limited stops, feature attractive stations, and use a bus-only street in Richmond. 


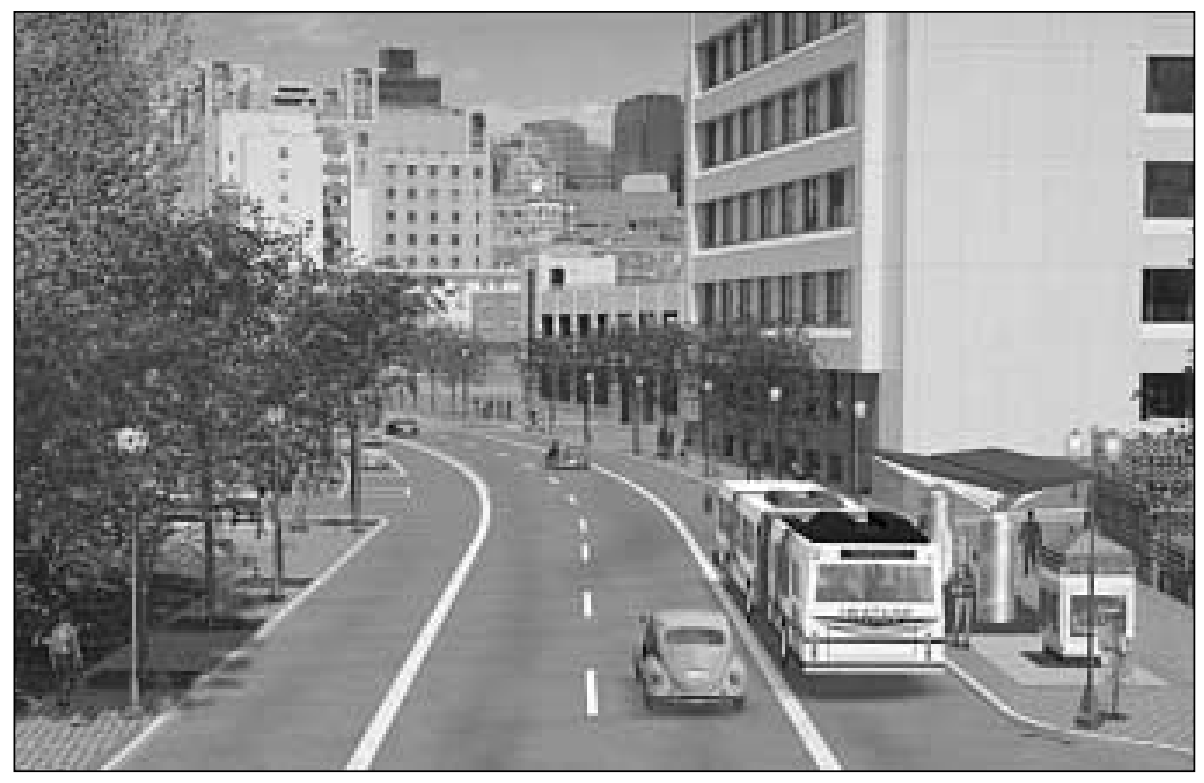

Figure 11. Boston's BRT express service will extend over the existing Ted Williams Tunnel to Logan National Airport.

South America. Major BRT systems have been implemented in Belo Horizonte, Curitiba, and São Paulo, Brazil; Quito, Ecuador; and Bogotá, Colombia. These systems typically use physically separated median lanes along wide multilane arterial roadways. Stations are typically spaced 1,200 to 1,500 feet between major intersections, with provisions for overtaking on some systems via passing lanes at stations. Multidoor articulated (18 meter) and biarticulated (24.5 meter) diesel and trolley buses are used, depending on the system, and several systems offer off-vehicle fare collection. Peak-hour, peak-direction passenger flows range from 10,000 to 20,000 persons per hour (Gordon, Cornwell, and Cracknell 1991).

Of these systems, the Curitiba operation is perhaps the best known. Curitiba's BRT system is an integral part of the City's development strategy, and it is carefully integrated with adjacent development. Biarticulated buses operate in a median busway that is flanked by local service streets. In addition, express buses run on two parallel high-capacity one-way streets. 
The BRT stations in Curitiba are located in "plastic tubes" with high-level platforms that match the floor height of the BRT buses. The stations also feature off-vehicle fare collection at the ends of the tubes to expedite passenger flows and reduce dwell times. However, station and vehicle design limit bus operations to the median busways.

The twelve key attributes of the Curitiba system include:

1. simple route structure,

2. frequent service at all times of day,

3. headway-based as opposed to time-point schedules,

4. less frequent stops,

5. level boarding and alighting,

6. color-coded buses and stations,

7. exclusive lanes,

8. higher-capacity buses,

9. multiple-door boarding and alighting,

10. off-vehicle fare payment,

11. feeder bus network, and

12. coordinated land-use planning.

Curitiba's busways carry about 188,000 daily passengers in the north-south corridor, 80,000 in the Boqueirao corridor, 52,000 in the east corridor, and 19,000 in the west corridor. The highest, peak-hour, peak-direction ridership is approximately 11,000 in the north-south corridor.

Europe. European BRT systems have several innovative features. Essen, Germany, and Leeds, England, have mechanically guided busways. Rouen, France, has an optically guided busway that uses the Irisbus Civis dual-mode diesel-electric bus (Figure 12). In Runcorn, England, the entire town is built around a largely grade-separated busway system.

Australia. Brisbane's South East Busway's attractive stations have received architectural awards for their innovative design (Figure 13). Only two years after the first segment opened, the (US) \$200 million 10.5-mile busway carries more 


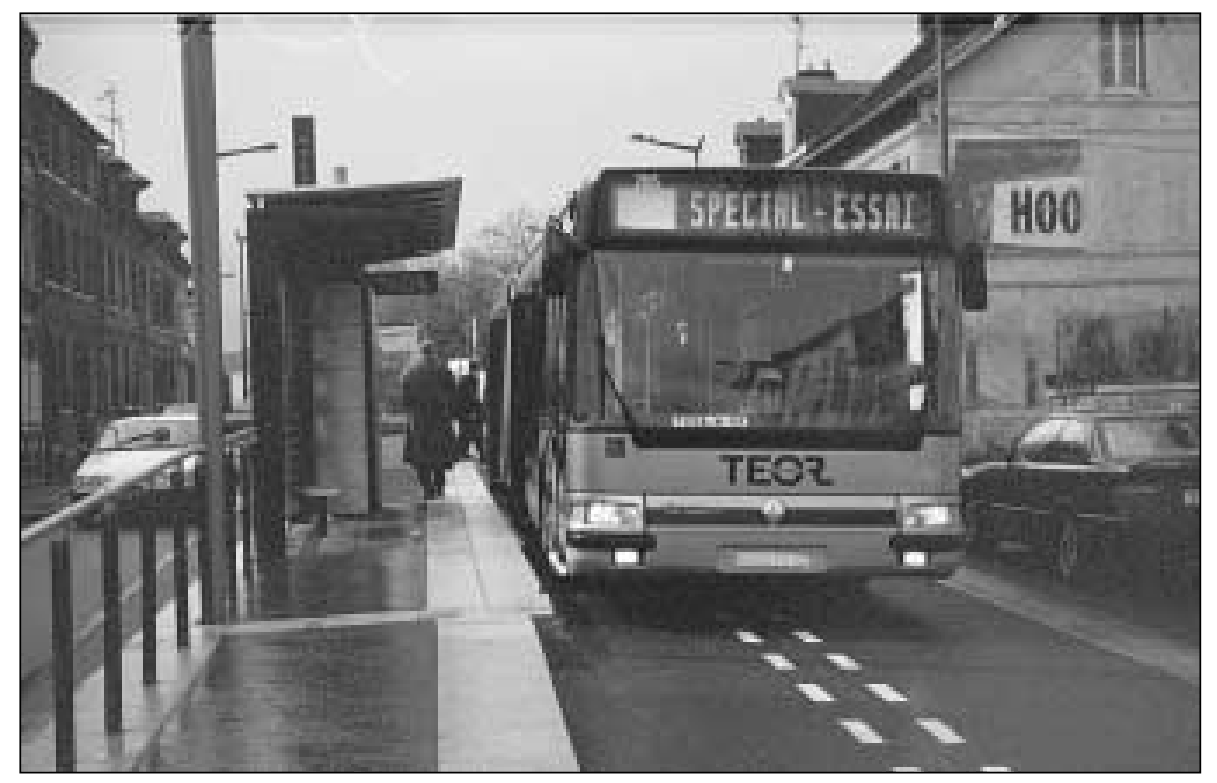

Figure 12. Rouen's optically-guided busway uses the Irisbus Civis dual-mode diesel-electric bus.

than 60,000 riders per day and has induced three major joint development projects (one already completed) as well as an increase in residential land values near stations 20 percent higher than similar areas not within walking distance of stations.

Adelaide operates a mechanically guided busway that enabled an elevated transit structure to be built with minimum width and cost. The 7.4-mile guided Adelaide busway, opened in stages between 1986 and 1989, has three major stations, carries 20,000 daily riders, and planning is underway for its expansion. During peak periods, buses operate through suburban neighborhoods and then access the busway for a high-speed, express run to the urban core. During off-peak periods, some routes only provide feeder service to an on-line, all-stops local route.

\section{Lessons Learned}

Comparison of the examples described above demonstrates a number of similar attributes. Several lessons can be drawn from the case studies, many of which were conducted as part of the TCRP A-23 project on "Planning and Implementation Guidelines for Bus Rapid Transit." The major lessons learned can be organized into the following categories: 
- planning and project development process,

- system concepts and packaging,

- running ways,

- stations,

- vehicles,

- system identity and image,

- service plan,

- ITS applications, and

- fare collection

Many of the lessons learned apply to planning and implementation for any rapid transit mode even though they were derived from the synthesis of BRT experience.

\section{Planning and Project Development Process}

Early and continued community support for an open planning process that objectively considers BRT is essential, particularly from elected leaders. It is important that decision-makers and the general community understand the nature of BRT and its potential benefits during the planning process and not assume that BRT is just additional bus service. BRT's potential performance, customer and developer attractiveness, operating flexibility, capacities, and costs should be clearly identified in alternatives analyses that objectively consider other alternatives as well.

The key rapid transit planning issue in many urban environments is how best to match market needs with available rights-of-way, not necessarily what mode to use. Accordingly, BRT system development should be the outgrowth of a planning and project development process that stresses problem solving and addresses demonstrated needs, rather than advocating a particular solution.

Successful BRT implementation usually requires participation of more than just transit operator/implementers. All prospective actors, especially highway implementer/operators should be a formal part of the planning process. For example, participants may include representatives of private sector transit operators as well as the police departments that may ultimately be responsible for 


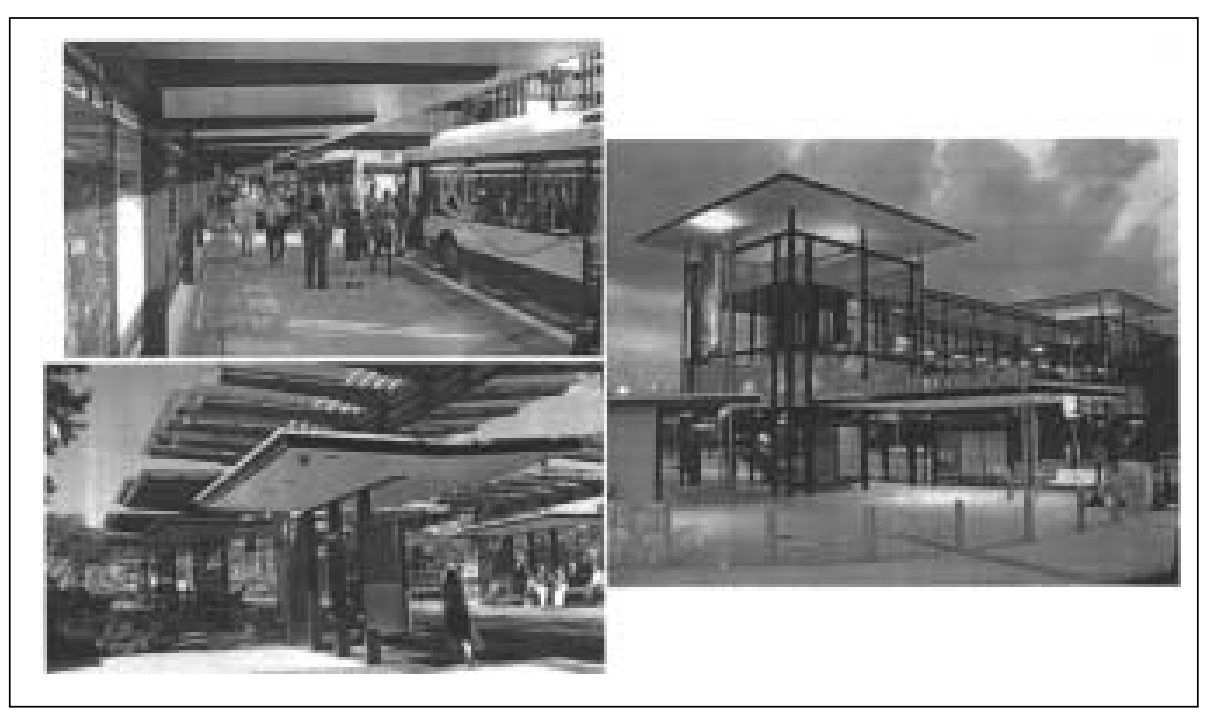

Figure 13. BRT stations Brisbane: South East Busway

enforcing exclusive transit running ways, as well as the safety and security of transit workers and customers.

BRT and land-use planning for station areas should be integrated as early as possible. Ottawa, Pittsburgh, Brisbane, and Curitiba have demonstrated that BRT can have land-use benefits similar to those produced by rail rapid. Realizing these benefits requires close coordination of land-use and transport planning from the beginning.

In many cases, it may be useful to identify a BRT segment for immediate, early implementation. This will demonstrate BRT's potential benefits as soon as possible at an affordable cost while enabling system expansion and upgrading (e.g., to more technologically advanced, dedicated BRT vehicles) at some future time.

\section{System Concepts and Packaging}

A successful BRT project that achieves its full potential calls for more than building or reserving a bus-only lane or even building a dedicated busway. The integration of the entire range of rapid transit elements, including stations, and development of a unique system image and identify are equally, if not more, important. 
BRT systems, like any rapid transit system, should be designed to be as costeffective as possible. However, transportation planners should not "cut corners" by eliminating key system elements and their integration merely because it would still be possible to attain minimal functionality of the bus system. This will greatly reduce potential benefits that can be achieved by a fully integrated BRT system.

It is essential that BRT systems include all the elements of any high-quality, high-performance rapid transit system. These elements should be adapted to BRT's unique characteristics, especially its service and implementation flexibility. There is a need to focus on service, station, and vehicle features and amenities and integrated system and "image" benefits, rather than merely costs. Bus rapid transit should be rapid. This best can be achieved by operating on exclusive traffic-free rights-of-way wherever possible, maintaining wide spacings between stations, and by minimizing dwell times at stops.

\section{Running Ways}

Though it is possible for buses to operate successfully in mixed traffic and even desirable for them to operate in bus or in HOV facilities in some markets, the ideal BRT system will operate over exclusive bus facilities for enhanced speed, reliability, and safety, and often overlooked, identity.

Railroad and freeway rights-of-way offer opportunities for relatively easy acquisition and low development costs. However, the availability of right-of-way should be balanced with its proximity and access to key transit markets.

Where a BRT commuter express service operates on an HOV facility, it is imperative that it have its own access/egress ramps to reach off-line transit stations and/or do collection/distribution in other ways. Requiring BRT vehicles to weave across multiple lanes of general traffic to access median HOV lanes should be avoided.

In identifying and designing BRT running ways, it is important to consider identity and image as well as speed and reliability.

The positive aspects of curb bus lanes are good pedestrian access and more manageable integration with turns at intersections. The negative aspects are delays from right-turning vehicles and competing use of curb space by delivery and service vehicles. 
The positive aspects of median BRT facilities on arterial streets are identity, avoidance of interference with access to adjacent land uses, and minimum "side" impedance. Wide streets are needed to accommodate BRT service along with general vehicular traffic. The negative aspects are interference with left turns and potential pedestrian access problems, which sometimes may be alleviated by special traffic signal phasing sequences.

\section{Stations}

Stations are perhaps the most critical element in achieving system identity and image.

Safe pedestrian and auto access to BRT stations is critical to achieving ridership objectives. Context-sensitive design and community involvement will both ease BRT implementation and induce transit-oriented land-use development.

Off-vehicle fare collection and suitable passenger amenities are desirable at major boarding points.

\section{Vehicles}

Vehicles are an important element of conveying system identity and image. There is general recognition of the need for greater focus on vehicle quality and identity for BRT systems, especially in the United States. Several manufacturers, such as Irisbus, Bombardier, and Neoplan, are starting to recognize this need by producing special BRT vehicles.

BRT vehicles should be configured to specific BRT applications as to number and width of doors, internal layout, etc. In the case of BRT systems, one size definitely does not fit all.

Focus should be placed on customers, both on- and off-board, by designing for ease of passenger entry/egress, on-board comfort, and cleaner air and noise emissions.

It is desirable to operate BRT systems with fleets of specially dedicated BRT vehicles.

\section{System Identity and Image}

System identity and image are important. As a minimum, they provide the customer with information on where to access the system and routing.

Identity and image alone can increase ridership in a competitive, consumeroriented society. 
Identity and image should be emphasized and be consistent in the design of all BRT system physical elements, including stations, vehicles, and running ways. Special graphics, livery, and construction materials can combine not only to convey useful information (e.g., where to catch a BRT service), but also to provide constant advertising exposure.

\section{Service Plan}

BRT service can extend beyond the limits of dedicated guideways where reliable, high-speed operations can be sustained. Outlying sections of BRT lines, and in some cases CBD distribution, can use existing roads and streets. These running ways should be modified to improve BRT efficiency, effectiveness, and identity through the use of graphics, signage, pavement markings, and appropriate traffic controls.

A key feature of BRT systems is their ability to provide point-to-point oneseat rides because of the relatively small size of their basic service unit compared to train-based modes. This, however, must be balanced against the need for easyto-understand, high-frequency service patterns at all times of day.

In most North American urban corridor applications, the BRT service pattern that appears to work best features all-stop "LRT type" service at all times of day, complemented by an overlaid integrated local/express services for specific markets during peak periods, such as express service between major park-andride stations and the CBD. During off-peak periods, integrated local/express routes are turned back at BRT stations, converting the local portion of the routes into more cost-effective feeders.

Where transfers are necessary, they should take place in station facilities that are attractive, offer amenities, and are designed to minimize walking distances and level changes.

\section{ITS Applications}

ITS elements are critical to the success of BRT and can, at relatively modest cost, replace some of the functions provided by the physical infrastructure for other types of rapid transit. ITS elements can be used to convey passenger information in a variety of venues, monitor/control bus operations, provide priority at signalized intersections, enhance safety and security on board vehicles and at stations, and provide guidance for BRT vehicles. 
In places where ITS elements have been applied most successfully to BRT, they have been applied as part of an integrated regional transportation system, as in Los Angeles.

\section{Fare Collection}

Off-board fare collection is desirable because it is more convenient for customers. It permits multiple-door boarding, thereby reducing station dwell times, passenger travel times, and bus operating costs.

Some on-board fare collection mechanisms can support multiple-door boarding, but they must be carefully selected. ITS or smart card technology applied at multiple doors may be the key to allowing simultaneous "on-board" fare payment and multiple-door boarding without increasing revenue shrinkage.

\section{Significance and Extension}

BRT does work! Recent developments around the world have shown that BRT systems can provide high-quality, high-performance, attractive rapid transit in a variety of settings. A growing number of cost-effective systems demonstrate the potential to produce significant service, ridership, and development benefits at relatively modest initial implementation and operating costs.

Looking ahead, there will be a growing number of fully integrated BRT applications, and even more use of selected elements. The recent introduction of attractive, flexible, rubber-tired, "dual-mode" purpose-built BRT vehicles into revenue service is likely to have a profound effect on accelerating the acceptance of BRT as a true rapid transit mode in a number of ways. First, these vehicles overcome the image and identity problems BRT has had because of its link to conventional local bus services, especially in North America. Second, with true dual-mode (steered like a bus or guided like a train) capabilities, they can deliver the real, substantive benefits of both buses and rail transit, especially when running way and service plan improvements are also made. The resulting flexibility makes BRT a candidate for consideration in many rapid transit applications. The flexibility is especially important in North America with its wide diversity of urban land development patterns and modest capacity requirements.

At the same time, all communities may not have sufficient ridership mar-

kets or have financial or physical limitations that prevent implementation of a 
fully integrated BRT system. In those cases, many of the lessons learned concerning the individual components can be adopted by existing bus systems to improve their overall attractiveness and cost effectiveness.

\section{References}

BRT Bus Rapid Transit-Why more communities are choosing Bus Rapid Transit. 2001. Washington, DC: Transportation Research Board, National Research Council.

Federal Transit Administration. 1987. Issues in Bus Rapid Transit.

Federal Transit Administration. 1990. Bus Rapid Transit demonstration program.

Gordon, G., P. K. Cornwell, and J. A. Cracknell. 1991. The performance of busway transit in developing countries, Crowthorne, UK: Transport and Road Research Laboratory.

Harrington, P., R. F. Kelker, and C. E. DeLeuw. 1937. A comprehensive local transportation plan for the City of Chicago.

Levinson, H. S., et al. 1973, 1975. NCHRP Reports 143 and 155. Bus Use of Highways. Washington, DC: Highway Research Board, National Research Council.

Mass transportation survey-National capital region, civil engineering report. 1959. DeLeuw Cather \& Co. (January).

Metropolitan Transportation Authority. 2000. Final report. Los Angeles Metro Rapid Demonstration Program.

Milwaukee area transit plan: A mass transit technical study. 1971. BartonAschman Associates (June).

Thomas, E. 2001. Presentation at Institute of Transportation Engineers meeting, Chicago (August).

W. C. Gilman and Co. 1959. St. Louis metropolitan area transportation study. Prepared for the City of St. Louis and St. Louis County (August).

Wilbur Smith and Associates. 1966. Transportation and parking for tomorrow's cities.

Wilbur Smith and Associates. 1970. The potential for Bus Rapid Transit.

Wilbur Smith and Associates. 1975. Bus Rapid Transit options for densely developed areas. 


\section{About the Authors}

HeRBERT S. LEVINSON (hslevinson@aol.com) is a transportation consultant who has worked for public agencies in the United States and abroad. He has written extensively on public transport, covering topics such as bus rapid transit, bus use of highways, transit operations, and transit capacity. Mr. Levinson is the coprincipal investigator for the TRB TCRP A-23 project on "Planning and Implementation Guidelines for Bus Rapid Transit Systems." He is a member of the National Academy of Engineering and an Urban Transportation Research Center mentor at City College, New York. He has a BS degree in civil engineering from Illinois Institute of Technology, and a certificate in highway traffic from Yale University.

SAMUel Zimmerman (sam.zimmerman @dmjmharris.com) is the principal for transportation planning for DMJM+Harris. Mr. Zimmerman is the coprincipal investigator for the TRB TCRP A-23 project. He is also the former director of planning for the Federal Transit Administration and has a career spanning 34 years in which his major interests have included travel demand forecasting, transit economics, and systems analysis. He has BCE and MCE degrees from Cornell University.

G. ScotT RutheRford (scottrut@u.washington.edu) is director of the transportation program and chairman of the civil engineering department at the University of Washington, where he has taught for more than 21 years. He received a Ph.D. in transportation from Northwestern University and has been a transportation planning consultant on numerous major transit projects. His specialties are travel demand forecasting, transit and traffic operations, and major transportation investment planning. Dr. Rutherford is a member of the TCRP A23 project team.

Jennifer Clinger (jennifer.clinger@dmjmharris.com) is a senior transportation planner with DMJM+Harris, where she consults in the areas of transportation planning, economics, and finance. She is a member of the TCRP A-23 project team. Ms. Clinger holds a master's degree in regional planning from the University of North Carolina and a bachelor's degree in city planning from the University of Virginia. 